\title{
Graells y Agenjo en GRAELLSIA
}

\author{
I. Izquierdo Moya \& C. Martín Albaladejo
}

Queremos traer hoy a estas páginas el recuerdo de dos naturalistas de nuestro país, ambos entomólogos y estrechamente relacionados con la revista. El primero de ellos (fig. 1), Mariano de la Paz Graells y Agüera (1809-1898), descubridor y autor de la especie de lepidóptero que da nombre a la misma y, a su vez, homenajeado por otro autor, el americano Augustus Grote, quien creyó oportuno crear en 1896 el género Graellsia para la Saturnia isabellae Graells, 1849 (figs. 3-4) -más tarde isabelae-. Y el segundo (fig. 2), Ramón Agenjo Cecilia (1908-1984), quien tuvo un destacado papel en la creación de una nueva serie periódica, fundada en 1943 en el seno del Consejo Superior de Investigaciones Científicas, cuyo título GRAELL-

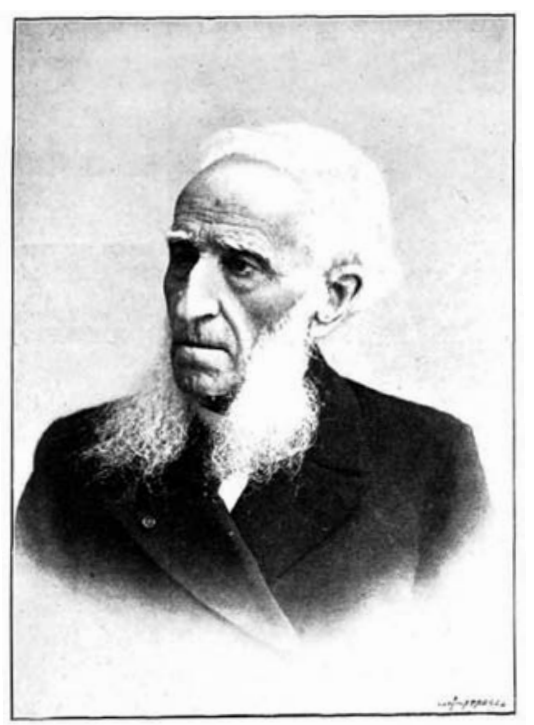

Fig. 1.- Mariano de la Paz Graells (La Ilustración Española y Americana, 22/1/1898).
SIA, Revista De Entomólogos Españoles, hace honor a ambos, la mariposa y su autor. Movió a sus promotores la necesidad de establecer en ella un foro de comunicación para el entomólogo aficionado "...trabajadores idealistas que han puesto su voluntad y su trabajo en la construcción de lo que pudiéramos llamar un ladrillo en nuestro edificio entomológico...”, y donde éstos pudieran “... seguir sus actividades hasta cristalizar en aportaciones positivas para el conocimiento de nuestra fauna entomológica, misteriosa y nueva aún, a estas alturas del siglo $X X$, en la mayor parte del territorio español..." [Gonzalo Ceballos en la Presentación al Tomo I de GRAELLSIA, p. IV] (fig. 5). Perseguían por este medio el mismo objetivo que constituyó uno de los grandes empeños de Graells y al que dedicó gran parte de su obra, la catalogación de la

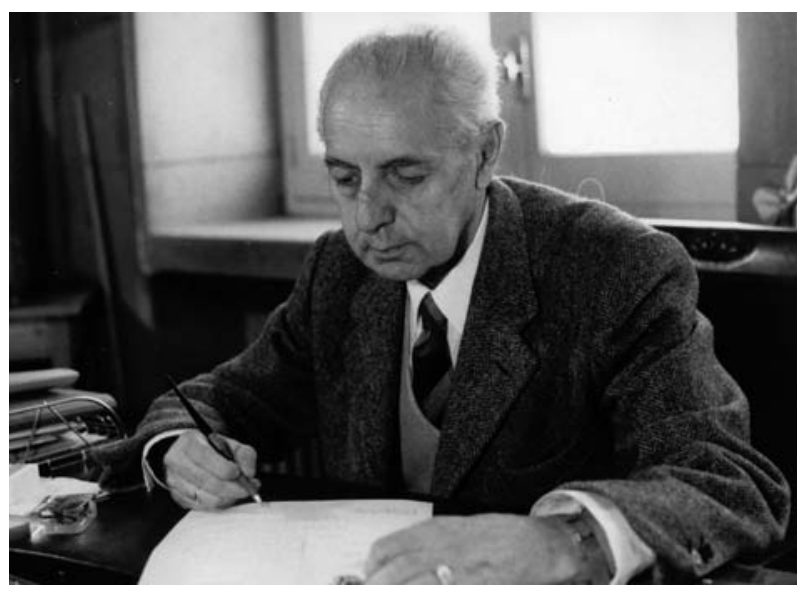

Fig. 2.- - Ramón Agenjo en el Instituto español de Entomología.

Fig. 2.- Ramón Agenjo in the Instituto español de Entomología. 


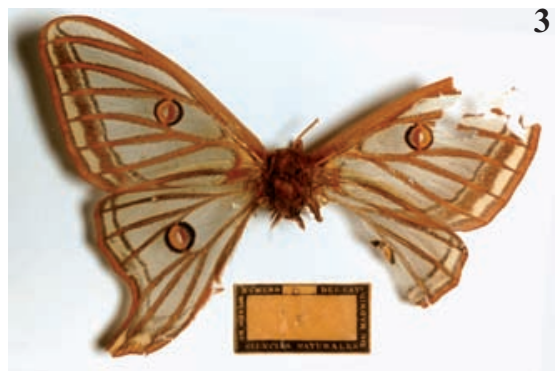

Figs. 3-4.- 3) Ejemplar de Actias isabelae. Colección Graells. 4) Neotipo designado por Agenjo en 1965.

Figs. 3-4.-3) Specimen of Actias isabelae of Graells' collection. 4) Neotype designated by Agenjo in 1965.

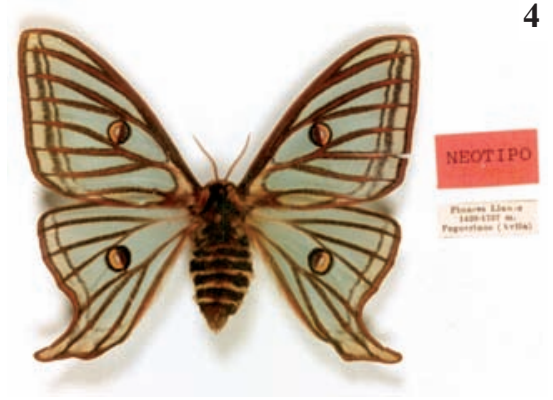

diversidad española de fauna y flora, “... Váyanse formando sucesivamente muchos catálogos de los objetos que produce nuestro suelo, que de ellos resultará el índice general de la Historia natural española." [Graells, 1846. Catálogo de Moluscos Terrestres y de agua dulce observados en España]. Las numerosas revisiones, listados faunísticos y citas de capturas aparecidos durante la trayectoria de la revista, y el propio Catálogo Ordenador de Agenjo publicado por partes en la misma entre 1946 y 1977, se han dirigido al mismo fin.

GRAELLSIA iniciaba su camino inaugurando la andadura con una extensa biografía de Graells, firmada por Agenjo. Desde aquí les recomendamos su lectura, en verdad amena y rica en información y datos del naturalista decimonónico y de su época. Les invitamos igualmente a que dediquen unos minutos a repasar el artículo de Agenjo conmemorativo del volumen XXV de GRAELLSIA de 1970,

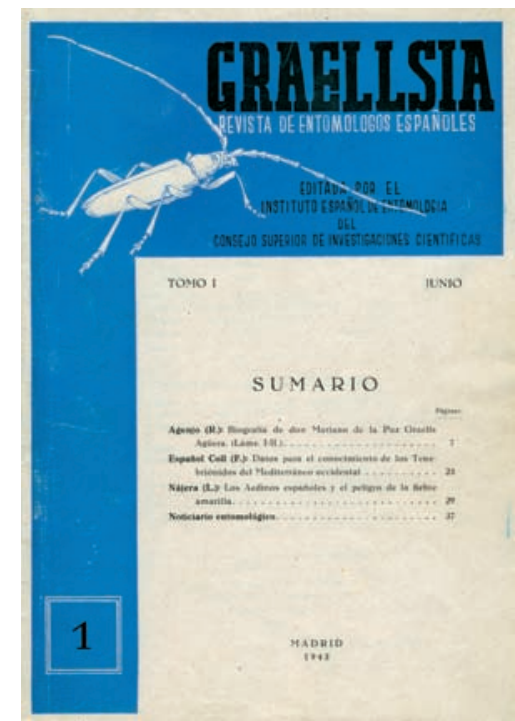

Fig. 5.- Portada del primer número de GRAELLSIA.

Fig. 5. - Front page of an exemplar of the first volume of GRAELLSIA. en el que tras una sucinta historia de los orígenes de la revista, ofrece casi un centenar de mensajes recibidos de prestigiosos entomólogos de todo el mundo, como reconocimiento a la consideración científica alcanzada por la publicación y en apoyo de la misma, en un momento en que por razones presupuestarias había peligrado su continuidad. Hoy afortunadamente, no parece correr riesgos la vida de la revista, pero sí la permanencia científica del género que le da nombre, ante las propuestas que desde hace años lo sinonimizan con el más antiguo Actias Leach, 1815. En éste, la isabelae de Graells se reúne, entre otras especies, con la norteamericana luna (Linneo, 1758) de tan notable parecido con nuestra mariposa endémica que fue justificadamente confundida con ella por Juan Mieg, su primer avistador.

Al finalizar este año 2008, coinciden en el tiempo ambos personajes y por ello hemos querido reunirlos en esta reseña. El pasado 21 de enero hizo un siglo del nacimiento de Ramón Agenjo en Madrid y en breve, el día 24 del próximo mes de enero, se cumplirá el segundo centenario del de Graells, nacido en el pueblo de Tricio en La Rioja.

Quede aquí esta noticia conmemorativa, dedicada a ambos y a su labor, como referentes imprescindibles que son en la historia de la Entomología española.

\section{AGRADECIMIENTOS}

Queremos dar las gracias a Jesús Muñoz, del Servicio de Fotografía del MNCN, por su amabilidad y eficacia en el tratamiento de las imágenes. 